\title{
ESTUDO COMPARATIVO ENTRE A FORMA DO CONTORNO FACIAL E O CONTORNO DO INCISIVO CENTRAL SUPERIOR DIREITO
}

*Acadêmicos do III Semestre do Curso de Graduação da FO/UFRGS

* Prof . Orientador. Profo do Departamento de Odontologia Preventiva e Social. Mestre em Saúde Pública

R.Fac.Odont., Porto Alegre, 27:67-89, 1985. 


\section{REFERÊNCIA BIBLIOGRÁFICA}

BIZZI, Fernando Junqueira et alii. Estudo comparativo entre a forma do contorno facial e o contorno do incisivo central superior. $R e$ vista da Faculdade de Odontologia de Porto Alegre, 27:67-89, 1985.

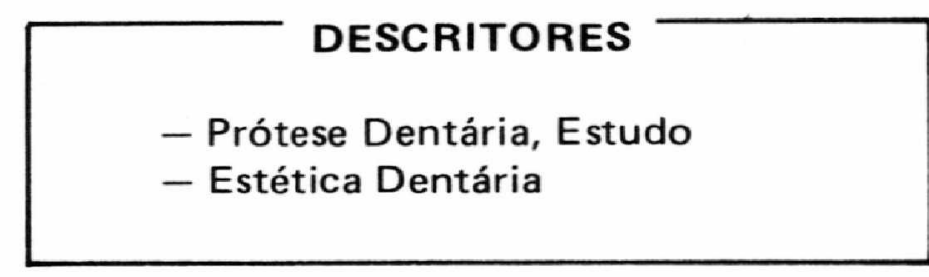

\section{RESUMO}

Os autores fazem uma análise de concordância entre a forma do contorno facial de treze estudantes de odontologia com a forma do contorno dos seus respectivos incisivos centrais superiores direitos, encontrando-se dez casos $(76 \%)$ de discordância, com o que parece não existir relação entre a forma facial e a do incisivo central superior. 


\begin{tabular}{|} 
ESTUDO COMPARATIVO \\
ENTRE A FORMA DO \\
CONTORNO FACIAL E O \\
CONTORNO DO INCISIVO \\
CENTRAL SUPERIOR \\
DIREITO
\end{tabular}

\section{INTRODUÇÃO}

Este trabalho tem por finalidade investigar uma possível relação entre as formas dos incisivos centrais superiores direito com os tipos existentes de contornos faciais.

É importante saber se existe esta relação, principalmente quando um cirurgião realiza um trabalho de prótese dentária, pois se comprovada esta relação devemos mantê-la com fins estéticos, de modo que o paciente sinta-se bem com a sua nova aparência. A única maneira de fazè-lo é confeccionar uma dentadura com o máximo de fidelidade das características da dentição perdida.

Por haver certas divergências de autores a respeito da existência ou não desta relação, incentivados por sugestões de alguns professores, propusemo-nos a estudar este aspecto em alunos da Faculdade de Odontologia da Universidade Federal do Rio Grande do Sul, a fim de darmos nossa contribuição no sentido de esclarecer esta incógnita.

\section{REVISÃo BIBLIOGRÁFICA}

Durante odesenvolvimento daprótese dentária, cirurgiões dentistas e pesquisadores sentiram necessidade de melhorar e facilitar a seleção de dentes artificiais para dentaduras completas com intuito de promover uma "terceira dentição" com aparência natural.

A teoria dos temperamentos foi aprimeira universalmente aceita para seleção de dentes artificiais. Baseava-se na teoria clássica, que dominou na medicina antiga, que afirmava a existência de quatro temperamentos fundamentais: linfático, sangüineo, nervoso e bilioso.

Spurghein, citado por Aprile et alii $^{4}$, introduziu na prótese dentária, esta classificação de dentes em relação às características anatômicas, fisiológicas, psicológicas dos indivíduos, a fim de estabelecer uma sistematização no processo de seleção dos dentes artificiais para desdentados totais.

A seleção dos dentes pelo método dos temperamentos foi tornando-se obsoleta pela dificuldade em determinar exatamente o temperamento do paciente; como pela dificuldade ainda maior, em selecionar àquela forma de dente indicado para cada caso individual entre a grande variedade de formas dentárias existentes; tendo como conseqüência o surgimento de uma nova técnica de seleção.

G. W. Clapp ${ }^{2}$, em 1909, recomendava selecionar a forma do incisivo central superior de acordo com o método sugerido por Berry" , afirmando que "os dentes artificiais são oferecidos em tal variedade de formas que podem ser selecionados facilmente para harmonizar com qualquer face".

A teoria dos temperamentos persistiu em prótese dentária até que por sua pesquisa e senso artístico, L. Willians, citado por Aprile et alii $^{6}$, apresentou nova classificação de formas que permitem sistematização do processo de fabricação dos dentes artificiais, baseado nas formas típicas dentárias e sua correspondência com as formas faciais.

Em 1903, Berry ${ }^{1}$ recomendava escolher a forma dos dentes orientando-se pelo contorno da face:

"Trace uma linha transversal sobre a testa a meia distância entre as sobrancelhas e o limite do couro cabeludo. Trace a linha do contorno do rosto passando 
pelos ângulos do maxilar inferior até a testa. Corte a figura assim formada e verificará que ela tem exatamente a forma do incisivo central superior que corresponda a esta face".

\subsection{Forma dos Incisivos Centrais Supe- riores}

León Willians, citado por Aprile et alii $^{6}$, estabeleceu três formas fundamentais facilmente reconhecidas nas faces vestibulares dos incisivos centrais superiores.

São elas: quadrada, ovóide e triangular e mais as formas intermediárias.

Afirma Willians que existe relação entre estas formas e a do contorno facial (acrescenta que há relação entre as formas dos dentes anteriores e posteriores).

Diamond, citado por Aprile et alii ${ }^{3}$, estabeleceu uma série ou caracteres cujas modificações são as que provocam as distintas formas dos tipos de dente:

- Número de lóbulos que integram um dente

- Forma e contorno

“Estas modificações podem ocorrer em todos ou somente em alguns destes caracteres; na totalidade da peça dentária, em um ou vários de seus lóbulos de desenvolvimento; tão somente em um dos diâmetros de um ou mais destes lóbulos".

Coloca Diamond que:

a) Se os lóbulos crescem longitudinalmente, aparecerá um dente comprido no sentido ocluso cervical.

b) Se os lóbulos crescem no sentido mésio-distal, formar-se-á um dente largo.

c) Quando existe um deficit de desenvolvimento nas porções cervicais dos lóbulos mesial e distal, se reduz o diâmetro cervical e o dente adotará uma forma triangular.

Todas estas modificações da forma dentária obedecem a fatores congênitos, porém o dente pode alterar a sua forma por atrito com seu dente antagonista e por abrasão que determina diminuição da altura coronária nos bordos incisais, cúspides e rebordos marginais, diminuição do diâmetro mésio-distal pelo desaparecimento do ponto de contato.

\section{DESENHO DAS FORMAS DE INCISIVOS CENTRAIS SUPERIORES SEGUNDO WILLIANS:}
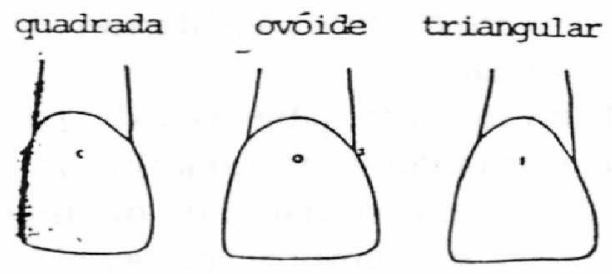

FORMA DE INCISIVOS CENTRAIS SUPERIORES SEGUNDO DIAMOND:

1. Dente comprido no sentido servical

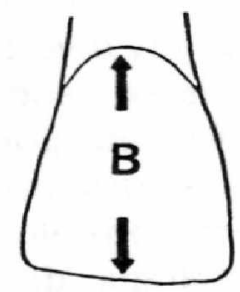

2. Dente largo

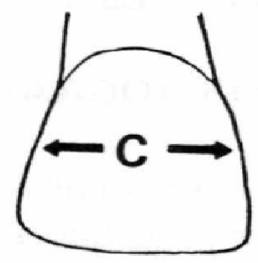

3. Dente triangular

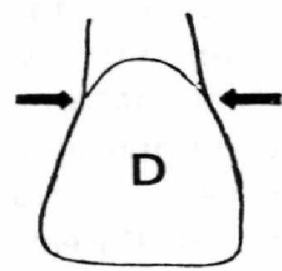




\section{:orma dos Contornos Faciais}

Segundo Dirsa Nogueira ${ }^{5}$, existem is formas clássicas de contornos faciais ue são: quadrado, triangular e ovóide. A partir disto podemos estabelecer um quadro com seis formas básicas:

Arredondada, ovóide, quadrada, retangular, triangular eqüilátero e triangular isóceles e quatro formas mistas:

Arredondada triangular, ovóide triangular, quadrada triangular e retângulo triangular.

"Geralmente as formas quadradas, retangulares, arredondadas e ovóides apresentam no contorno inferior do MENTO uma curvatura ampla e aberta enquanto as formas triangulares básicas e mistas apresentam uma curvatura mais fechada".

Dirsa Nogueira ${ }^{5}$, em 1961 conclui que a forma dos incisivos centrais naturais em geral não concorda com a forma do contorno facial, havendo significativa predominância de formas discordantes.

Segundo um trabalho realizado pelo Prof. Dr. Antonio Rosat ${ }^{*}$, este conclui que há uma relação dos contornos faciais com as formas dos incisivos centrais superiores.

\section{HIPÓTESE}

Existe uma relação entre a forma dos incisivos centrais superiores com os contornos faciais.

\section{MATERIAIS E MÉTODOS}

A pesquisa consiste num estudo em treze pessoas de cor branca, oito do sexo masculino e cinco do sexo feminino, numa faixa etária de dezoito a vinte $\mathrm{e}$ três anos, todas com dentição natural.

${ }^{*}$ Comunicação pessoal, 1985.
Estas pessoas na totalidade são estudantes da Faculdade de Odontologia de Porto Alegre da Universidade Federal do Rio Grande do Sul, escolhidos aleatoriamente.

\subsection{Material e Instrumental Utilizado}
a) moldeira tenax (superior)
b) espátula para gesso
c) tigela de borracha
d) alginato
e) gesso pedra
f) aparelho para vibração
g) desgastador de gesso
h) câmera fotográfica Asahi-Pentax
i) filme panotomic Kodak
j) lente para ampliação

\subsection{Métodos}

Para executar este estudo, foram realizados em cada indivíduo medidas, fotografias da face e modelo da arcada superior em gesso pedra precedido de impressão com alginato.

\subsubsection{Obtenção do Modelo da Arcada Dentária Superior}

Primeiramente posicionamos cada indivíduo em uma cadeira odontológica em um ângulo aproximado de $90^{\circ}$ enquanto preparamos o alginato nas seguintes proporções:

- Em moldeiras $S_{1}$ e $S_{2}$ foram utilizadas duas porções de pó alginato para duas porções de água.

- Em moldeiras $S_{3}$ foram utilizadas três porções de alginato para três de água.

Esta mistura foi espatulada numa tigela de borracha durante 45 s. Em seguida, preenchemos a moldeira e a levamos à boca do indivíduo em estudo, tomando a impressão. 
Aguardamos 3 a 4 minutos para retirada da moldeira. Imediatamente foi feito o vazamento da impressão com gesso pedra sob vibração na seguinte proporção:

- $100 \mathrm{~g}$ de gesso pedra adicionado a $30 \mathrm{ml}$ de água, sendo esta mistura espatulada numa tigela de borracha durante $1 \mathrm{~min}$.

O modelo foi manipulado após 24 horas desde o vazamento.

\subsubsection{Obtenção das Fotografias Faciais}

Tomamos uma fotografia da face de cada indivíduo em estudo numa ampliação de $9,5 \times 12,5 \mathrm{~cm}$.

As fotografias foram registradas da seguinte forma:

- Os indivíduos foram fotografados de frente em uma posição natural mantendo-se a mesma distância da câmera fotográfica ( 1 metro), mesmo ângulo de foco, sendo que a face fique totalmente enquadrada no eixo ótico.

\subsubsection{Obtenção das Fotografias dos In- cisivos Centrais Superiores Direi- to}

As fotografias foram registradas a partir dos modelos de modo que a face vestibular do dente fique totalmente enquadrada no eixo ótico da câmera mantendo mesmo ângulo de foco e uma distância de $15 \mathrm{~cm}$ entre o modelo e a câmera, com o auxílio de lente para ampliação.

\subsubsection{Determinação da Forma do Con- torno Facial.}

Para determinação da forma do contorno facial procuramos um método baseado em aspectos geométricos das formas e em conceitos de classificação.
Devido a definição do limite rior da face ser bastante arbitrári terminamos que a curvatura máxim. supercílios seja o limite superior da $f_{c}$

Traçamos sobre as ampliações $9,5 \times 12,5$ das fotografias da face, contorno facial de duas linhas paralelas a linha bipupilar e duas linhas perpendiculares às anteriores e tangentes, respectivamente, ao MENTO e a curvatura máxima dos supercílios e outras duas linhas perpendiculares as anteriores e tangentes aos bordos laterais da face.

Dividimos então a face em três segmentos horizontais, as linhas intermediárias traçadas constituem as linhas bizigomáticas e bigoniana.

Para determinarmos as formas do contorno facial, de modo a poder relacioná-la com as formas dos incisivos centrais superiores naturais, baseamo-nos nas três formas clássicas - quadrada, triangular e ovóide - e estabelecemos um quadro com seis formas básicas - arredondada, ovóide, quadrada, retangular, triangular equilátero, triangular isóceles - e quatro formas mistas ou combinadas - arredondada triangular, ovóide triangular, quadrada triangular e retângulo triangular.

Consideramos arredondada e ovóide as formas que apresentam o maior diâmetro na distância bizigomática, quadrada e retangular aquelas que apresentam as três linhas horizontais de referência aproximadamente iguais, e triangular equilátero e triangular isóceles, as que apresentam maior diâmetro frontal e gradativamente menores os inferiores.

As formas arredondada, quadrada e triangular equilátero constituem as formas curtas, em que o comprimento se equivale à largura máxima da face; as formas ovóide, retangular e triangular isóceles constituem as formas alongadas 
em que há predominio do comprimento sobre a largura máxima.

As formas combinadas quadrada triangular e retângulo triangular, apresentam largura bigoniana inferior as outras duas, que são mais ou menos equivalentes; as formas combinadas arredondada triangular e ovóide triangular, possuem o maior diâmetro na região bizigomática, porém a largura bigoniana é acentuadamente menor do que a largura frontal. A diferença entre as formas arredondadas triangular e ovóide triangular e entre as formas quadrada triangular e retângulo triangular, é apenas a proporção comprimento largura.

Geralmente as formas quadrada, retangular, arredondada e ovóide, apresentam no contorno inferior do mento uma curvatura ampla, aberta, enquanto as formas triangulares básicas apresentam uma curvatura mais fechada.

4.2.5. Determinação da Forma dos Incisivos Centrais Superiores Naturais, Vistos por sua Face Vestibular

Foram fotografados, com lente de ampliação de $9,5 \times 12,5 \mathrm{~cm}$ os incisivos centrais superiores dos modelos.

Classificamo-os segundo o critério e nomenclatura semelhantes aos que usamos para as formas dos contornos faciais, a fim de manter a sistematização do trabalho.

Foi orientado o incisivo central de modo que o eixo ótico da objetiva focasse perpendicularmente aos seus planos médio-distal e gengivo-incisal e passasse pela zona central.

Sobre as fotografias dos incisivos centrais superiores direitos, traçamos o eixo longitudinal do dente e duas linhas paralelas a este e tangentes, respectiva- mente, aos bordos mesial e distal, e outras ${ }_{i}$ duas linhas perpendiculares as anteriores e tangentes aos bordos gengival e incisal.

Dividimos a distância incisal em três partes iguais, por linhas perpendiculares ao longo eixo do dente, ficando a face vestibular seccionada em terços horizontais.

Adotamos a mesma classificação usada para os contornos faciais, para facilitar o estudo comparativo entre face e dente.

As formas arredondada, quadrada, triangular equilátero, arredondada triangular e quadrada triangular constituem as formas curtas, nas quais o comprimento e a largura mais ou menos se equivalem, enquanto as formas ovóide, retangular, triangular, ovóide triangular e retângulo triangular, constituem as formas longas nas quais há um predomínio do comprimento sobre a largura máxima.

Nas formas arredondada e ovóide, os bordos proximais são convergentes para incisal e para cervical, localizando a largura máxima no terço médio ou na união do terço médio com o incisal. A convergência cervical é pouco acentuada e a curvatura resultante é ampla, sendo a largura no terço cervical pouco menor que no terço médio e aproximadamente igual ao do bordo incisal.

Nas formas quadrada e retangular, os bordos proximais convergem paralelos entre si nos seus $2 / 3$ incisais, onde se localiza a largura máxima. A curvatura gengival é ampla, aberta.

Nas formas triangulares os bordos proximais convergem para cervical a partir do terço incisal onde se localiza a largura máxima. A convergência dos bordos proximais em direção ao longo eixo do dente forma uma curvatura gengival fechada, sendo bem menor a largura no terço cervical do que a largu- 
ra máxima no terço inferior.

As formas arredondada triangular e ovóide triangular são semelhantes as formas arredondada e ovóide respectivamente, porém a convergência dos bordos proximais é mais acentuada para cervical do que para incisal, sendo máxima a largura na união do terço médio com o terço incisal. A largura do dente ao nível do terço cervical é bem menor que nos $2 / 3$ inferiores e a curvatura gengival é mais fechada do que nas formas básicas correspondentes.

As formas quadrada triangular e retângulo triangular são semelhantes as formas quadrada e retangular, respectivamente porém seus bordos proximais são paralelos apenas no terço incisal ou até metade do terço médio e convergem para cervical no restante superior, sendo máxima a largura no terço incisal, a curvatura gengival resultante é fechada, sendo menor a largura no terço cervical do que nos terços inferiores.

\subsubsection{Definição de Concordância Exata}

Quando os tipos de contornos faciais e dentais coincidem, se define o caso como positivo de existência de concordância.

Ex. face ovóide com dente ovóide.

\subsubsection{Definição de Concordância Aproximada}

Quando os tipos de contornos faciais e dentais apresentam relativa concordância, se define o caso como positivo de existência de concordância.

Ex. face ovóide com dente arredondado, face quadrada triangular com dente retângulo triangular.

\subsubsection{Definição de Discordância}

Quando os tipos de contornos faciais e dentais não apresentam formas coincidentes, se define o caso como discordância.

Ex. face quadrada com dente triangular equilátero.

\section{RESULTADOS}

Caso 1: definido como discordância

Caso 2: definido como discordância

Caso 3: definido como discordância

Caso 4: definido como concordância aproximada

Caso 5: definido como discordância

Caso 6: definido como discordância

Caso 7: definido como discordância

Caso 8: definido como concordância exata

Caso 9: definido como discordância

Caso 10: definido como discordância

Caso 11: definido como concordância aproximada

Caso 12: definido como discordância

Caso 13: definido como discordância

\section{ANÁLISE DOS RESULTADOS}

Dos treze casos estudados, encontramos dez casos definidos como discordantes o que representa $76,9 \%$ e três casos definidos como concordantes, sendo dois casos de concordância exata que representa $7,7 \%$, perfazendo um total de $23,1 \%$ de casos concordantes.

Verificamos também que há um predomínio do contorno facial do tipo ovóide e sua forma derivada (ovóide triangular). No contorno do incisivo central superior direito encontramos um predomínio da forma triangular isóceles.

Estes resultados condizem com o trabalho realizado por Dirsa Nogueira ${ }^{5}$ 
no ano de 1961, porém, caem em contradição com as teorias de Diamond ${ }^{3}$ e León Willians ${ }^{6}$, citados por Aprile et alii $^{4}$ e do Prof. Antonio Rosat *.

Pensamos nós que esta relação dento-facial foi estabelecida por protesistas, com o intuito de facilitar e sistematizar a escolha de dentes artificiais para confecção de dentaduras. A partir dos nossos resultados podemos afirmar que este método de escolha não apresenta embasamento científico, apesar de solucionar de maneira "eficiente" o impasse de seleção de dentes artificiais.

\section{CONCLUSÕES}

Baseados nos treze casos conclui-se que:

a) não existe relação entre as formas do contorno facial com a forma do incisivo central superior direito.

b) há um predomínio da forma triangular isóceles nos incisivos centrais superiores direitos.

c) há um predomínio da forma ovóide e suas derivadas no contorno facial.

\section{AGRADECIMENTOS}

Queremos citar nossos sinceros agradecimentos ao:

- Prof. Dr. José Bastos D'Ávila

- Prof. Dr. Jorge Cordon

- Prof. Renato Oliveira

- Audio-Visual da Faculdade de Odontologia da Universidade Federal do Rio Grande do Sul.

- Professores e monitores da disciplina de Materiais Dentários

- Ricardo Q. D'Avila, acadêmico do curso de Arquitetura da Universidade Federal do Rio Grande do Sul.

. . que proporcionaram valiosíssi-

mas sugestões além de grande incentivo, e a todas aquelas pessoas que de alguma forma colaboraram para a concretização deste trabalho.

\section{SUMMARY}

The Authors make a concordance analisis between facial contour and the external line of the right upper incisive in 13 dental students.

They found discordance in ten cases $(76,9 \%)$. It seems that there is not relation between the facial contour and the external contour form of the incisive. 


\section{BIBLIOGRAFIA}

1. BERRY, F.H. apud NOGUEIRA, D. Seleção de formas e tamanho dos incisivos centrais superiores. Porto Alegre, 1961. p.18 Tese de Doutoramento apresentada à Faculdade de Odontologia da UFRGS.

2. CLAPP, G.W. apud NOGUEIRA, Dirsa. Seleção de formas e tamanho dos incisivos centrais superiores. Porto Alegre, 1961. p.18-20 Tese de doutoramento apresentada à Fac. de Odontologia da UFRGS.

3. DIAMOND apud APRILE, H. et alli. Anatomia odontológica orocervicofacial. 4.ed. Buenos Aires, EI Ateneo, 1967. p.327-8.

4. GARINO, R.R. Sistema dentário. In: Aprile, H. et alli. Anatomia odontológica orocervicofacial. 4.ed. Buenos Aires, El Ateneo, 1967.cap.8, p.315.529.

5. NOGUEIRA, Dirsa. Selação de formas e tamanho dos incisivos centrais superiores. Porto Alegre, 1961. 84p. Tese de Doutoramento apresentada à Faculdade de Odontologia da UFRGS.

6. WILLIAMS, L. apud APRILE, H. et alli. Anatomia odontológica orocervicofacial. 4.ed. Buenos Aires, El Ateneo, 1967. p.327. 

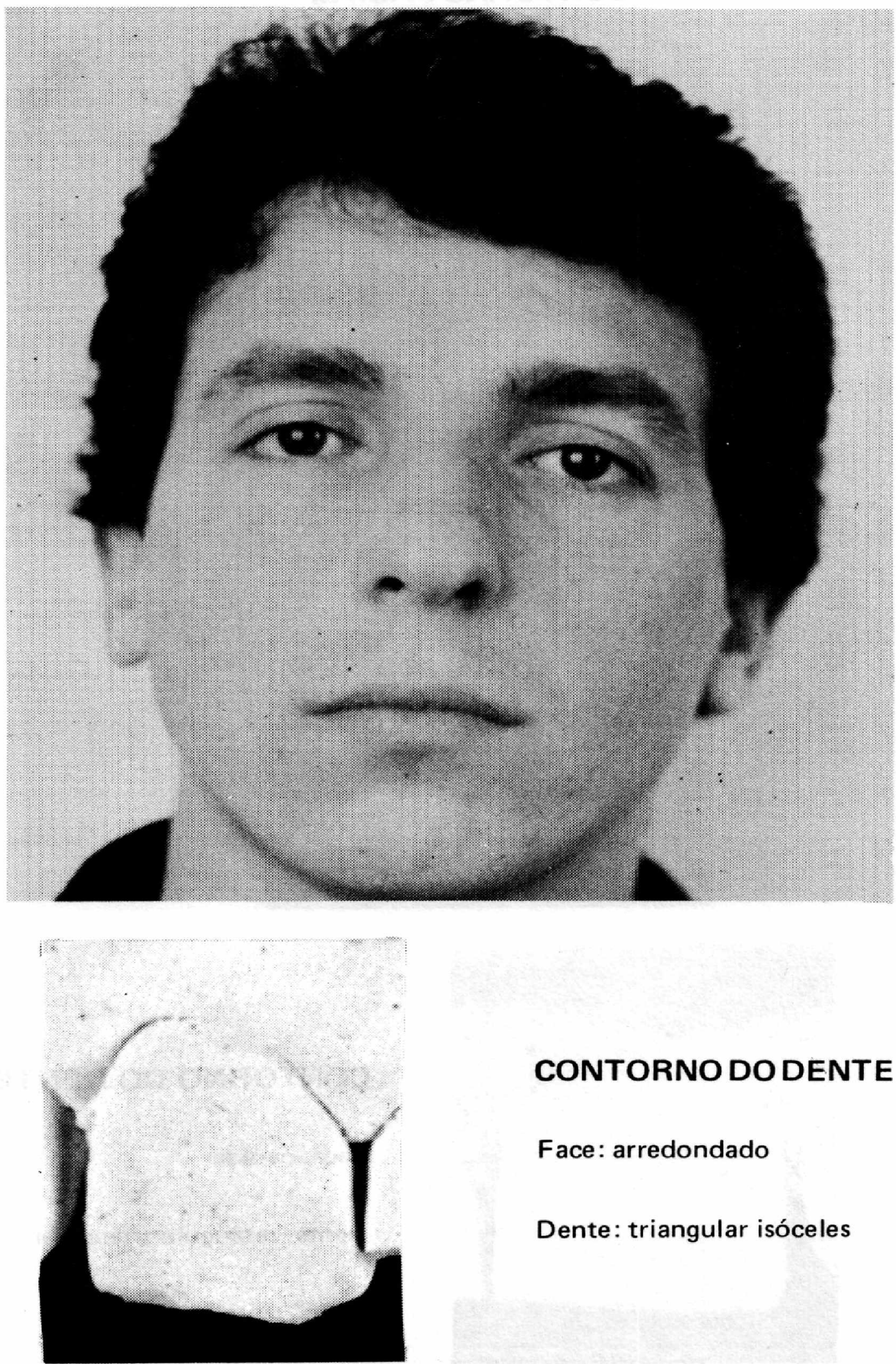

CONTORNO DODENTE

Face: arredondado

Dente: triangular isóceles 


\section{Caso 2}

\section{CONTORNO FACIAL}
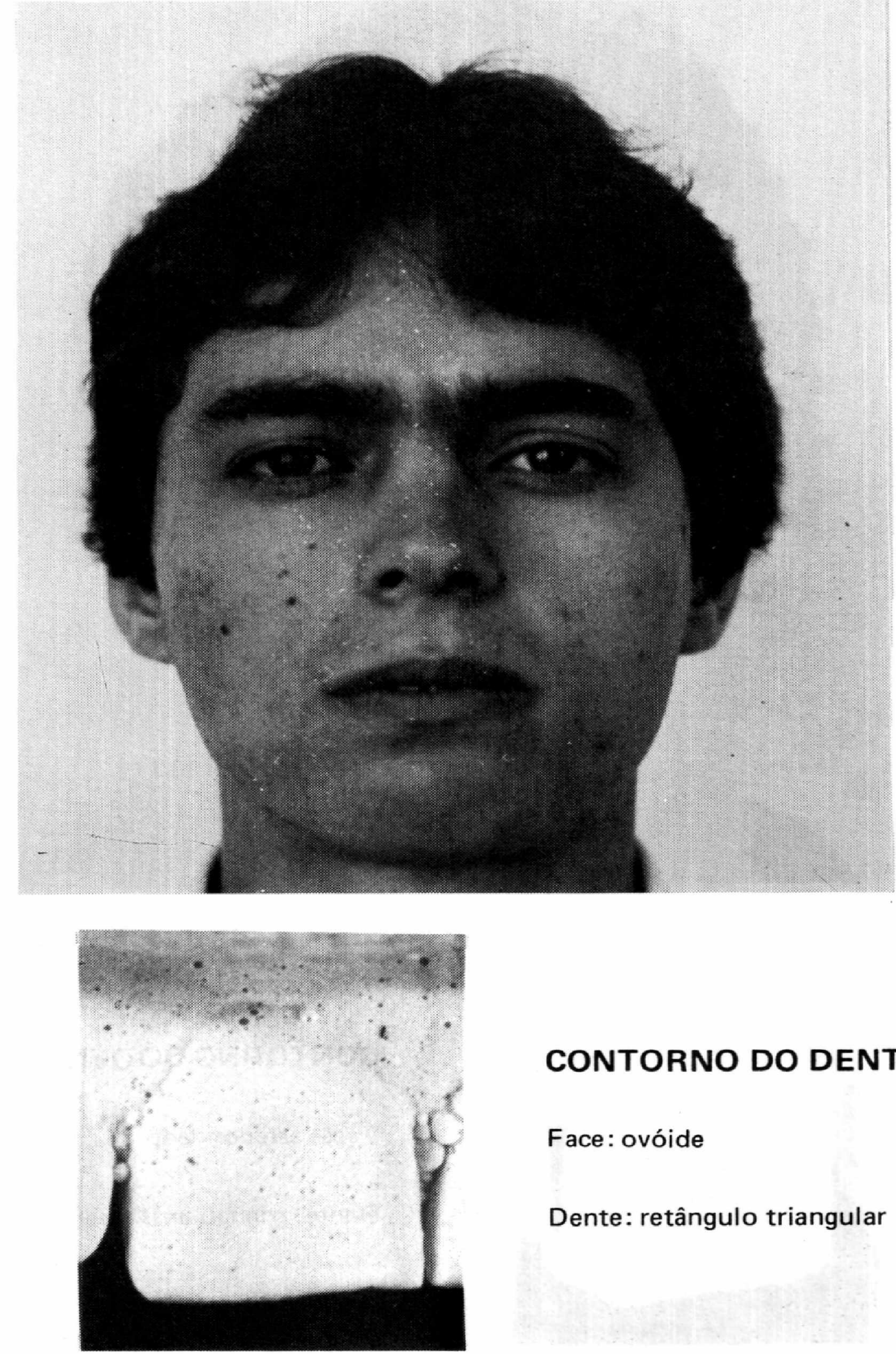

\section{CONTORNO DO DENTE}

\section{Face: ovóide}

Dente: retângulo triangular 


\section{Caso 3}

\section{CONTORNO FACIAL}
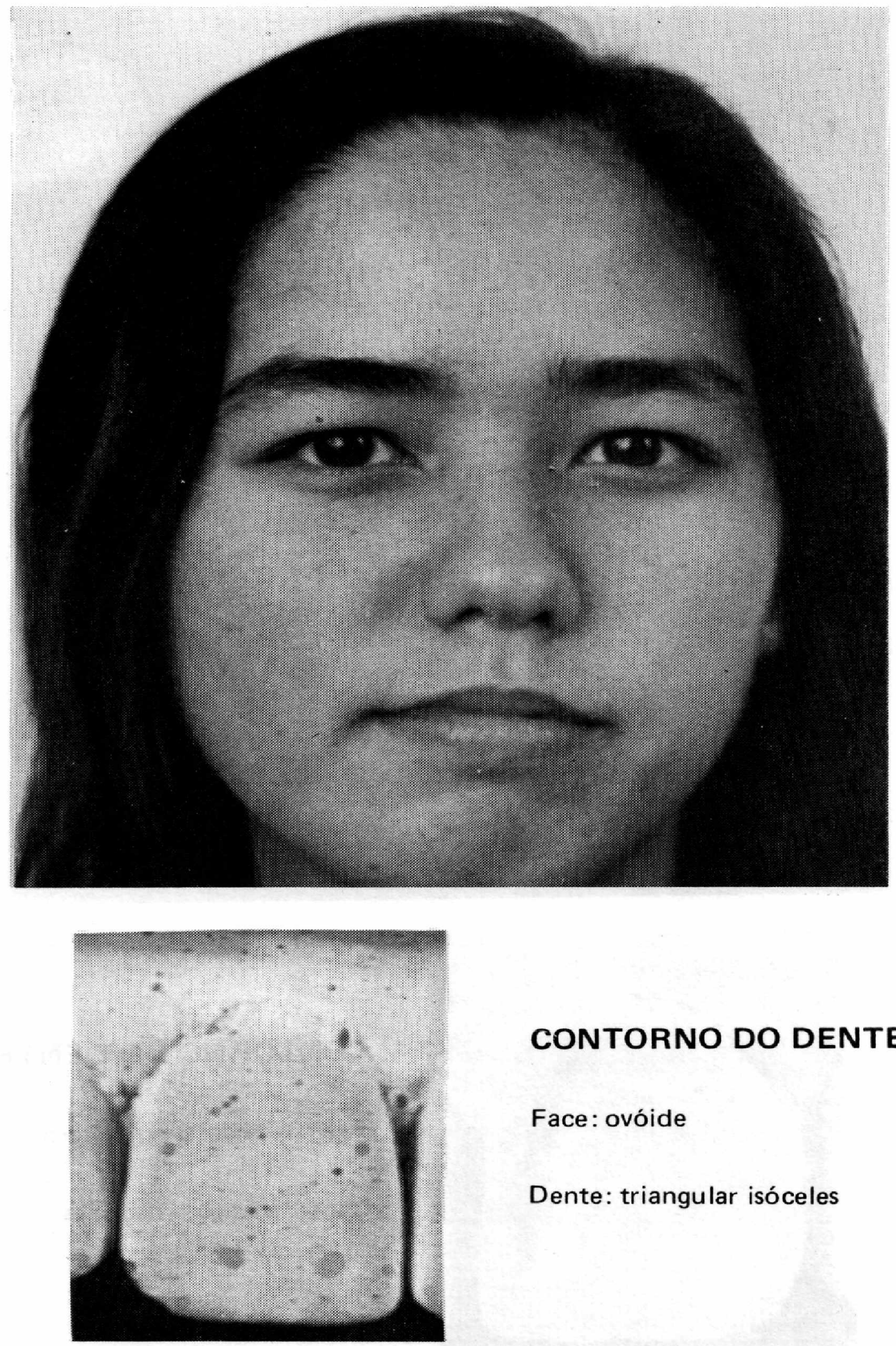

CONTORNO DO DENTE

Face: ovóide

Dente: triangular isóceles 
Caso 4 CONTORNO FACIAL
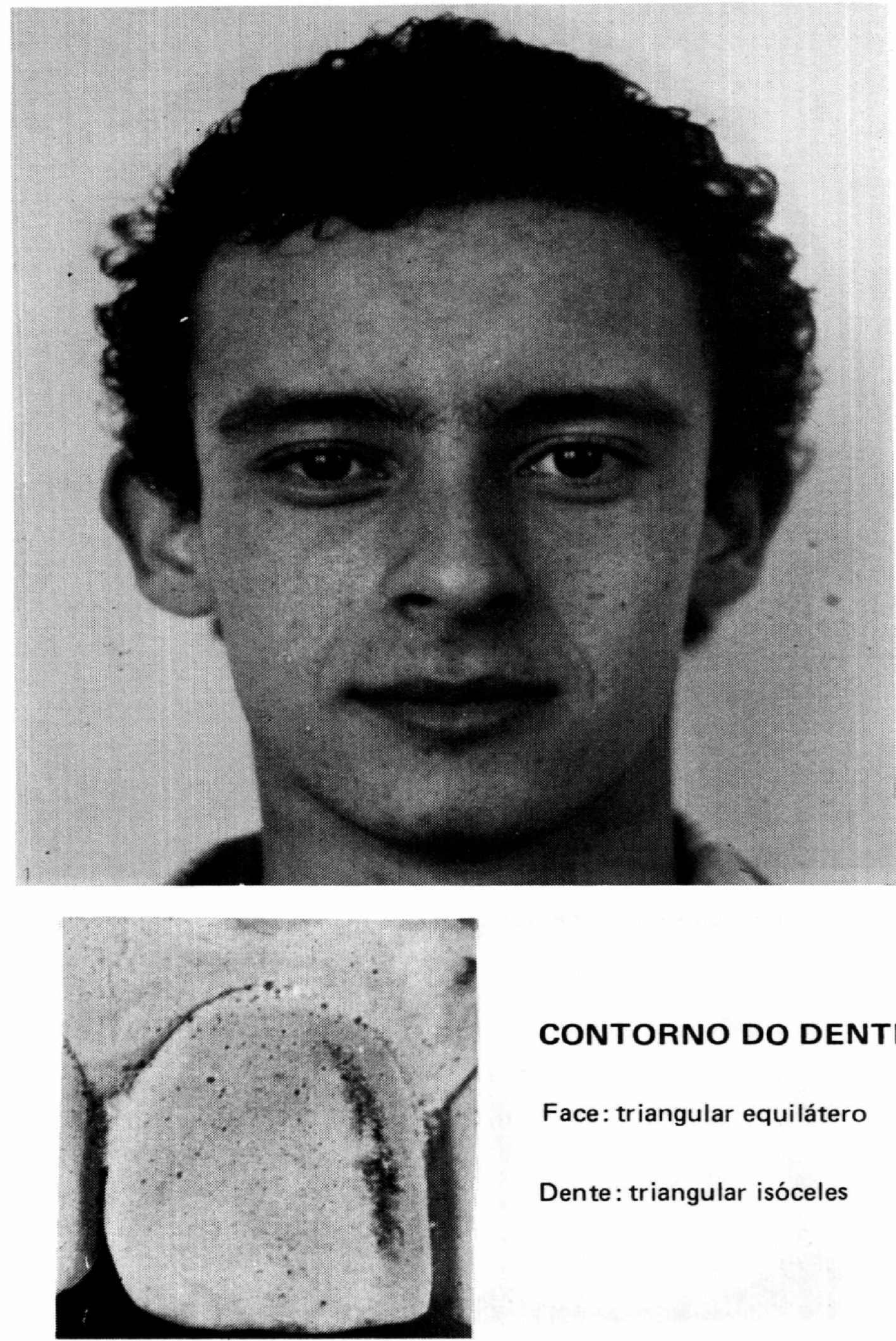

\section{CONTORNO DO DENTE}

Face: triangular equilátero

Dente: triangular isóceles 
Caso 5 CONTORNO FACIAL .
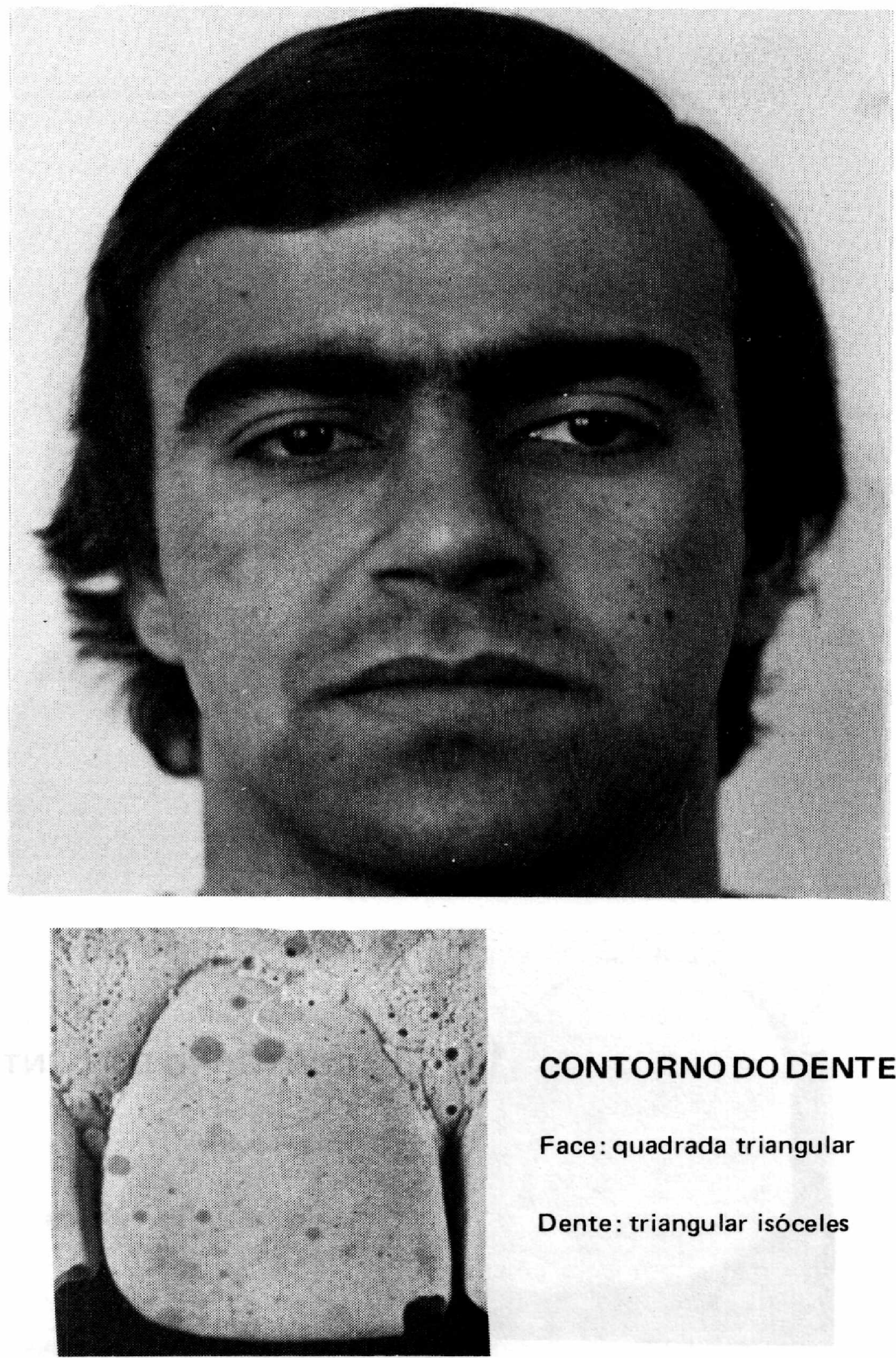

\section{CONTORNO DO DENTE}

Face: quadrada triangular

Dente: triangular isóceles

R.Fac.Odont., Porto Alegre, 27:67-89, 1985. 
Caso 6

CONTORNO FACIAL
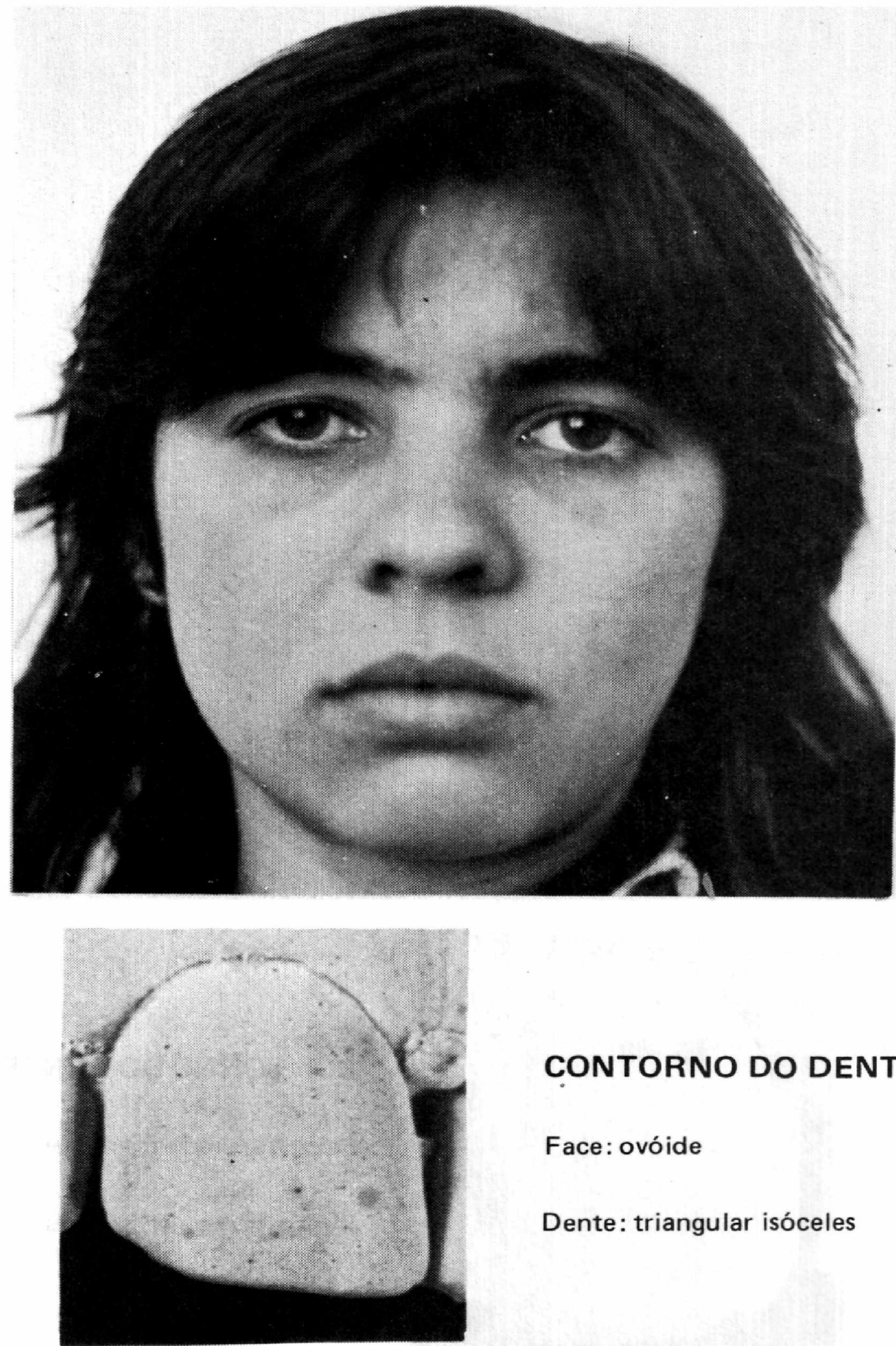

CONTORNO DO DENTE

Face: ovóide

Dente: triangular isóceles 
Caso 7

CONTORNO FACIAL
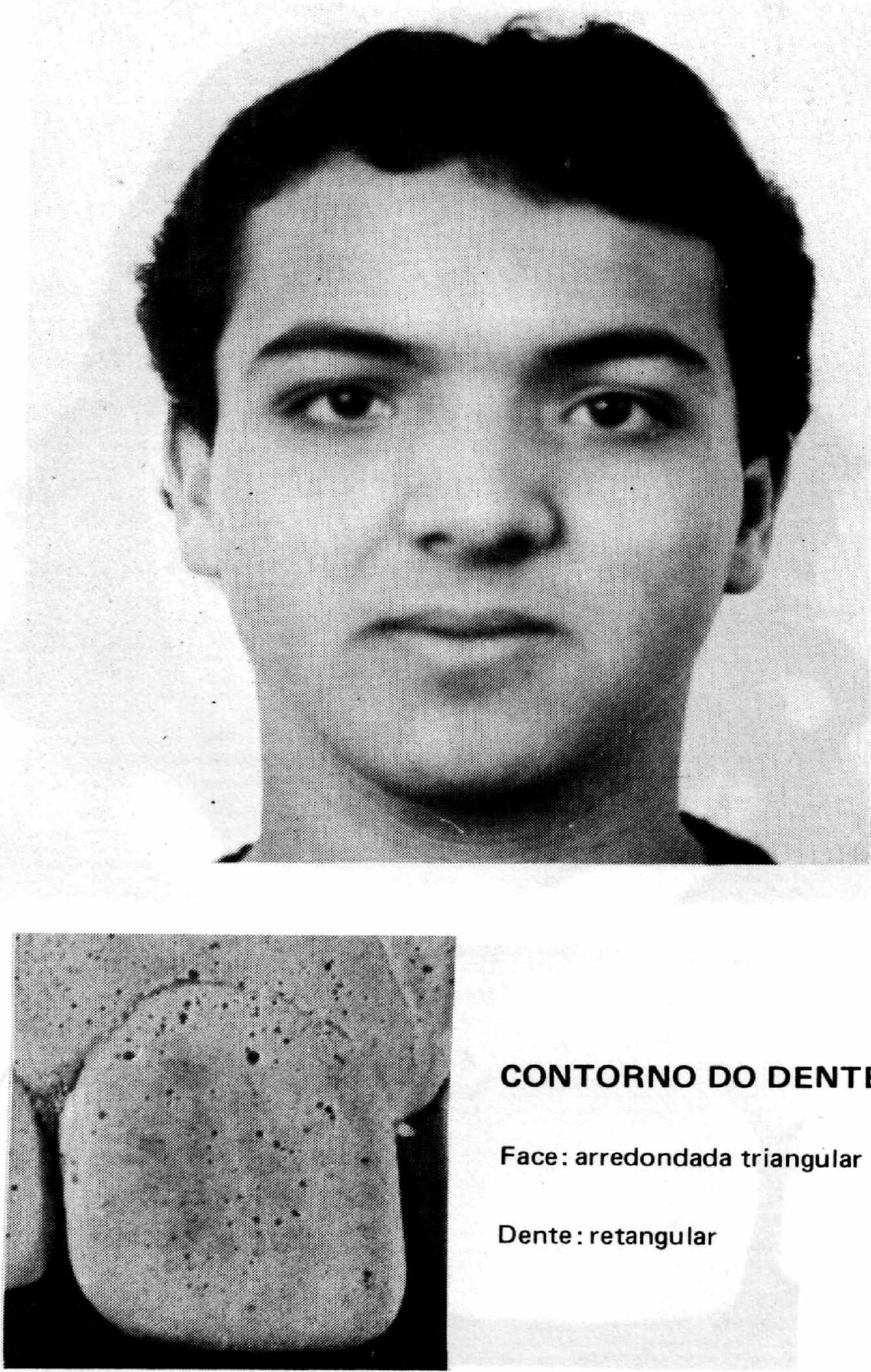

CONTORNO DO DENTE

Face: arredondada triangular

Dente : retangular

R.Fac.Odont., Porto Alegre, 27:67-89, 1985. 
Caso 8 CONTORNO FACIAL
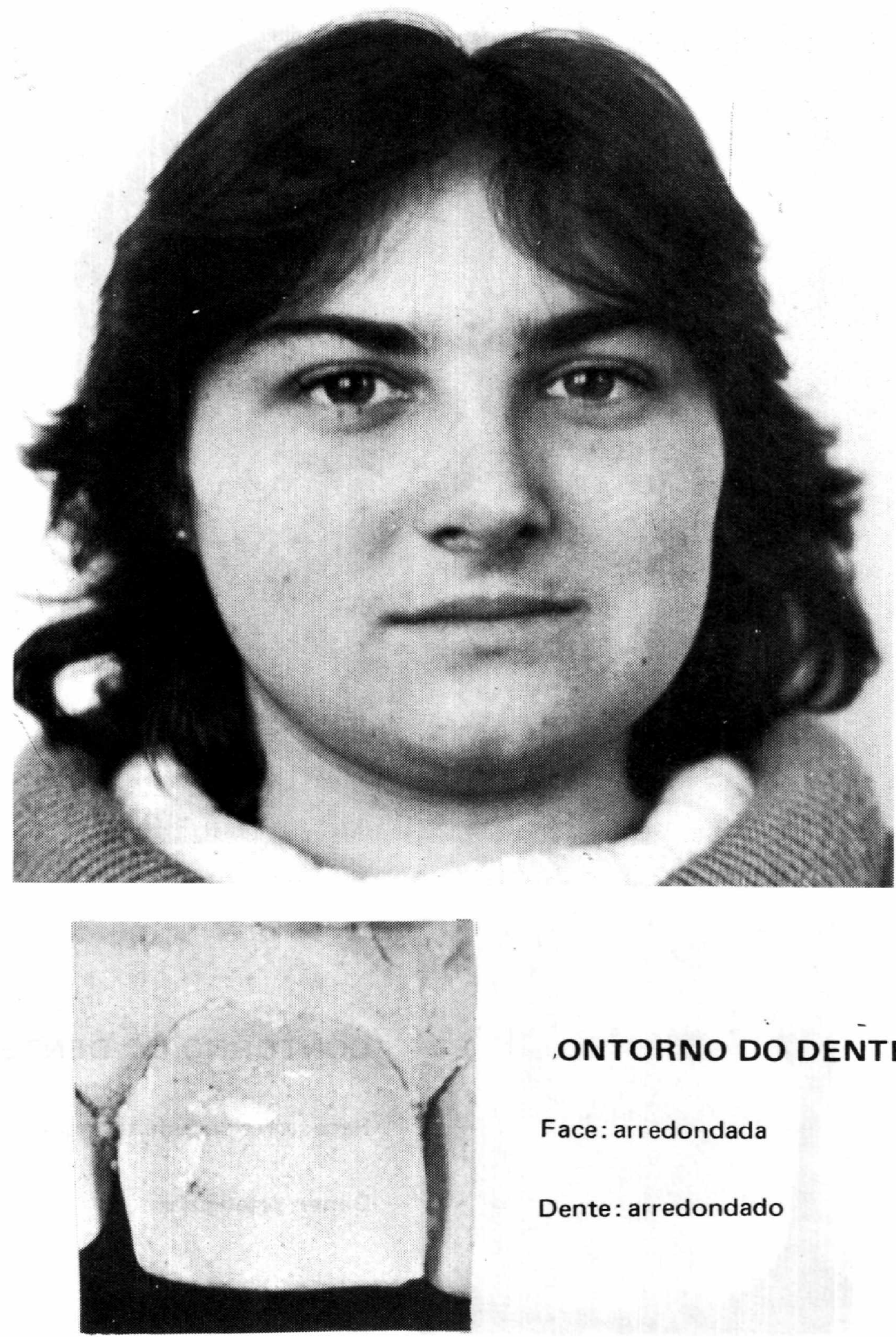

\section{ONTORNO DO DENTE}

Face: arredondada

Dente: arredondado 
Caso 9

CONTORNO FACIAL
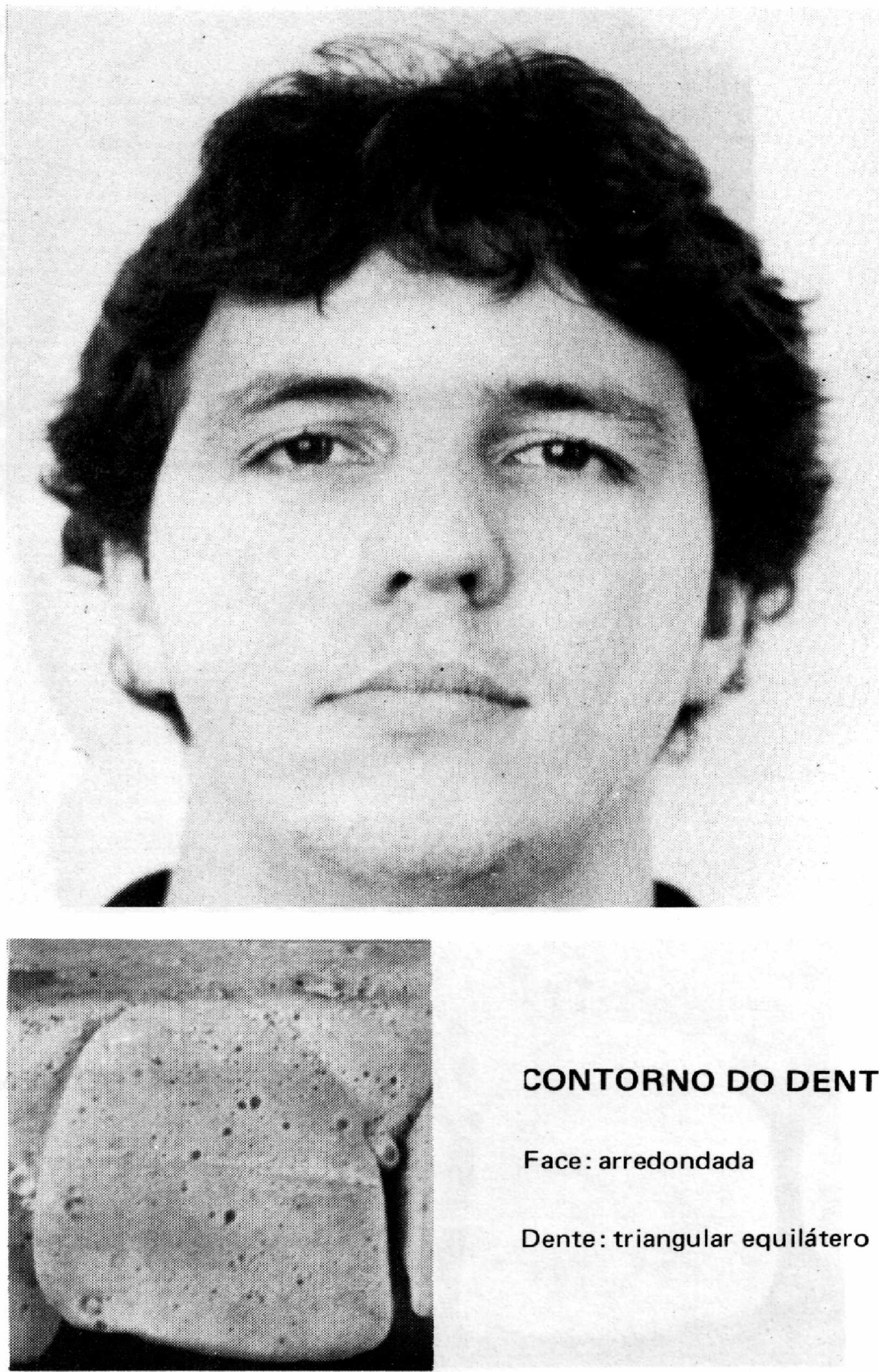

CONTORNO DO DENTE

Face: arredondada

Dente: triangular equilátero

R.Fac.Odont., Porto Alegre, 27:67-89, 1985. 
Caso 10

CONTORNO FACIAL
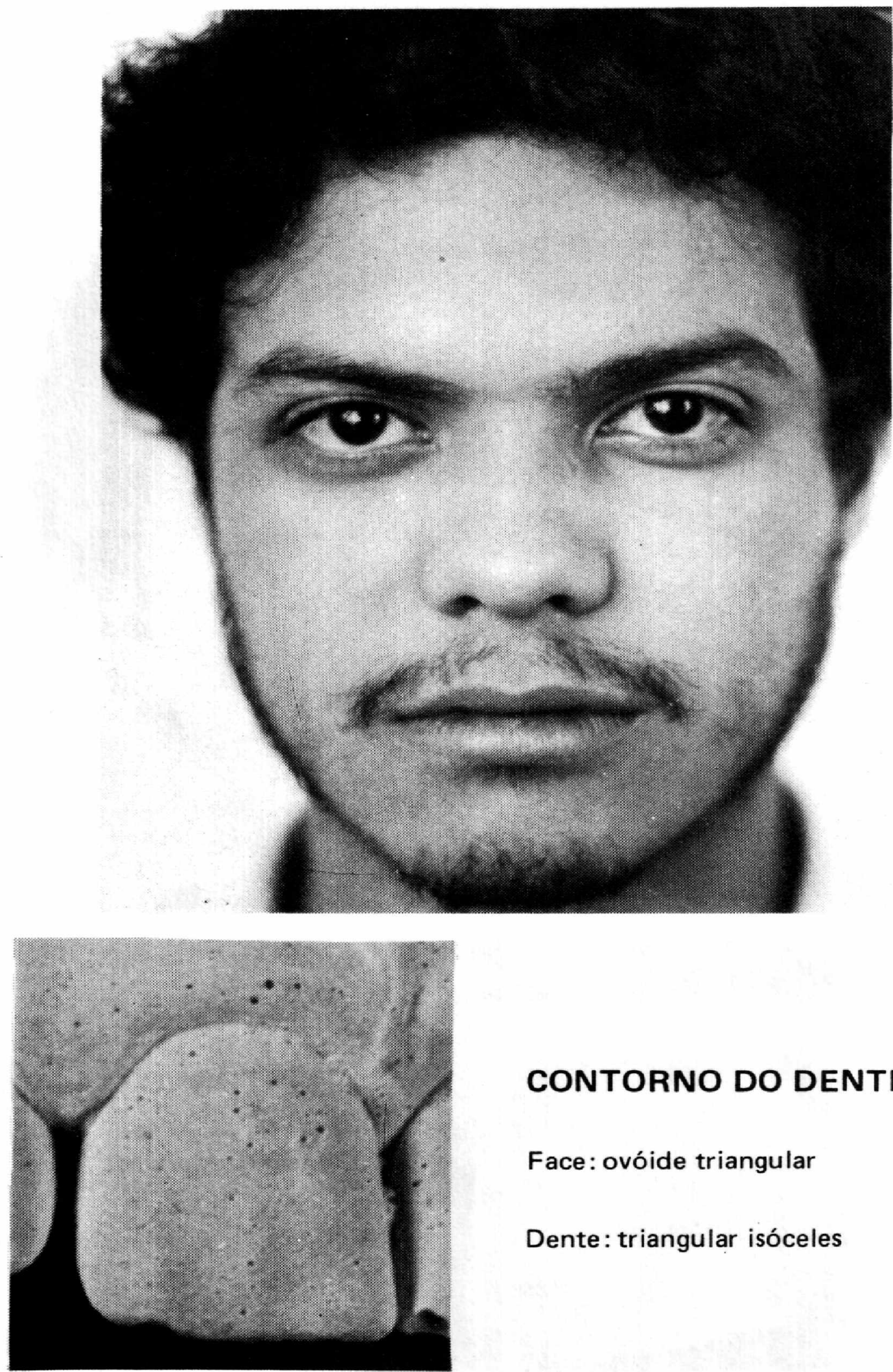

CONTORNO DO DENTE

Face: ovóide triangular

Dente: triangular isóceles 


\section{CONTORNO FACIAL}
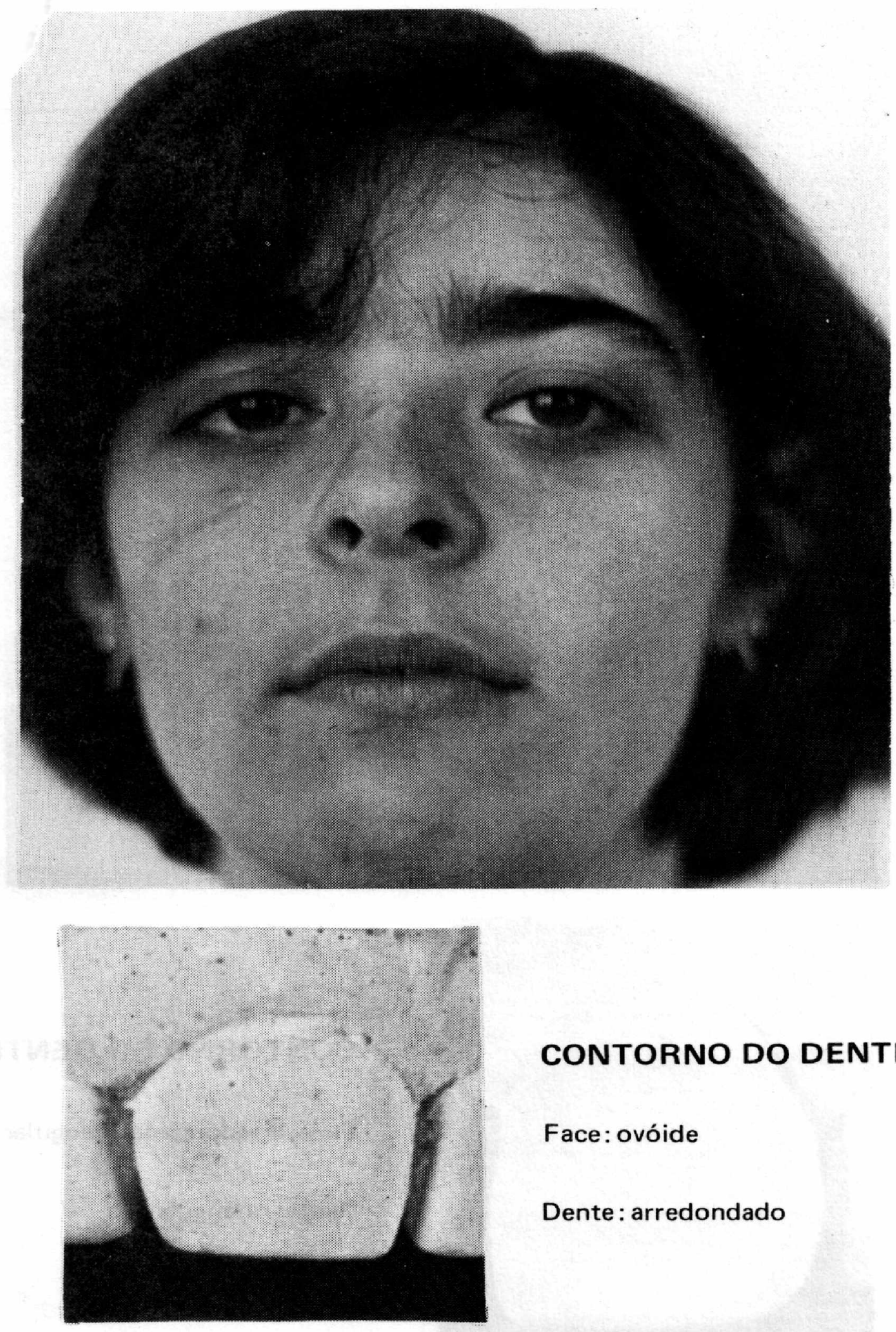

\section{CONTORNO DO DENTE}

Face: ovóide

Dente: arredondado

R.rac.Uaont., rorto Alegre, 27:67-89, 1985. 
Caso 12

CONTORNO FACIAL
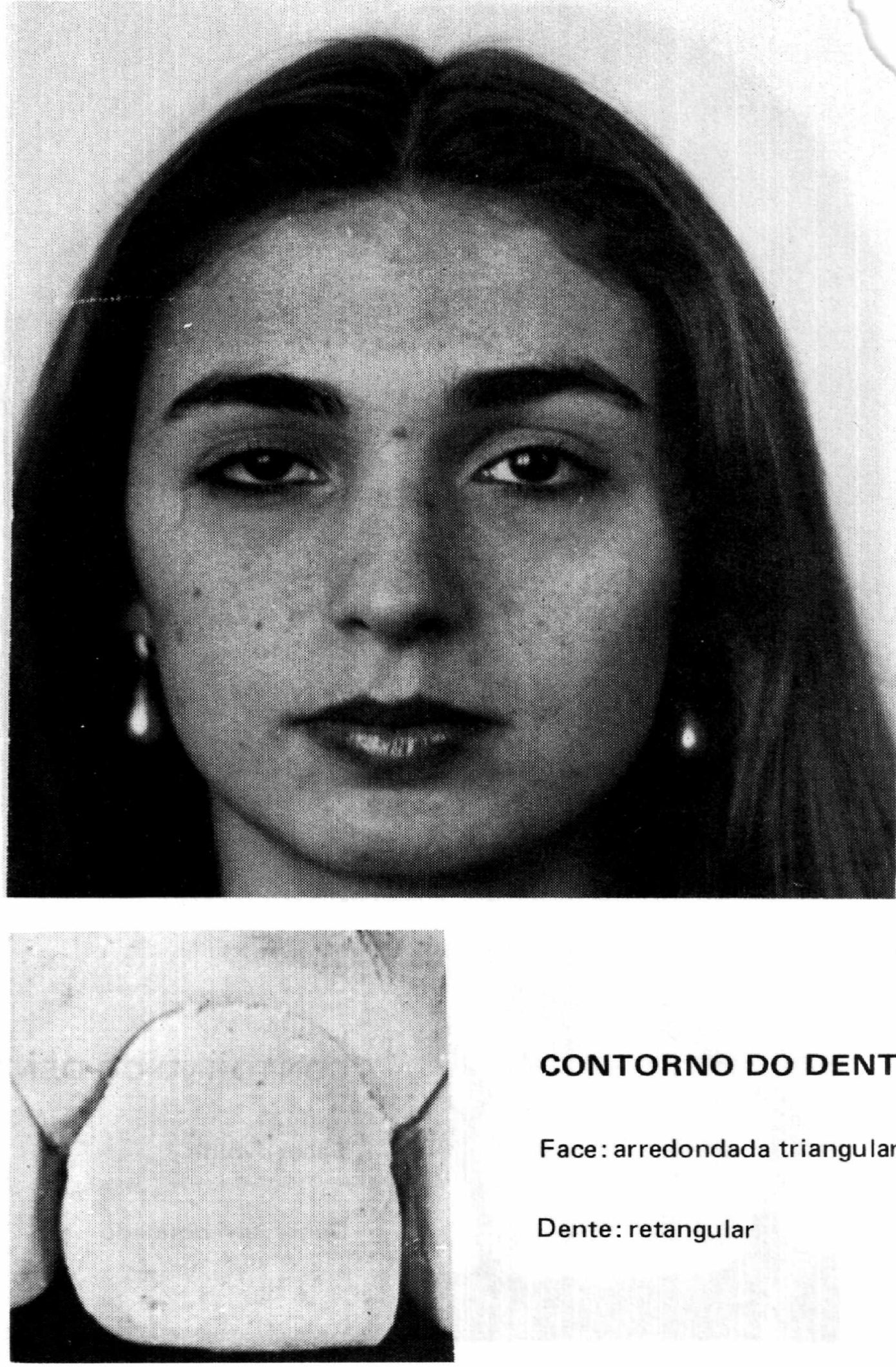

CONTORNO DO DENTE

Face: arredondada triangular

Dente: retangular 
Caso 13 CONTORNO FACIAL.
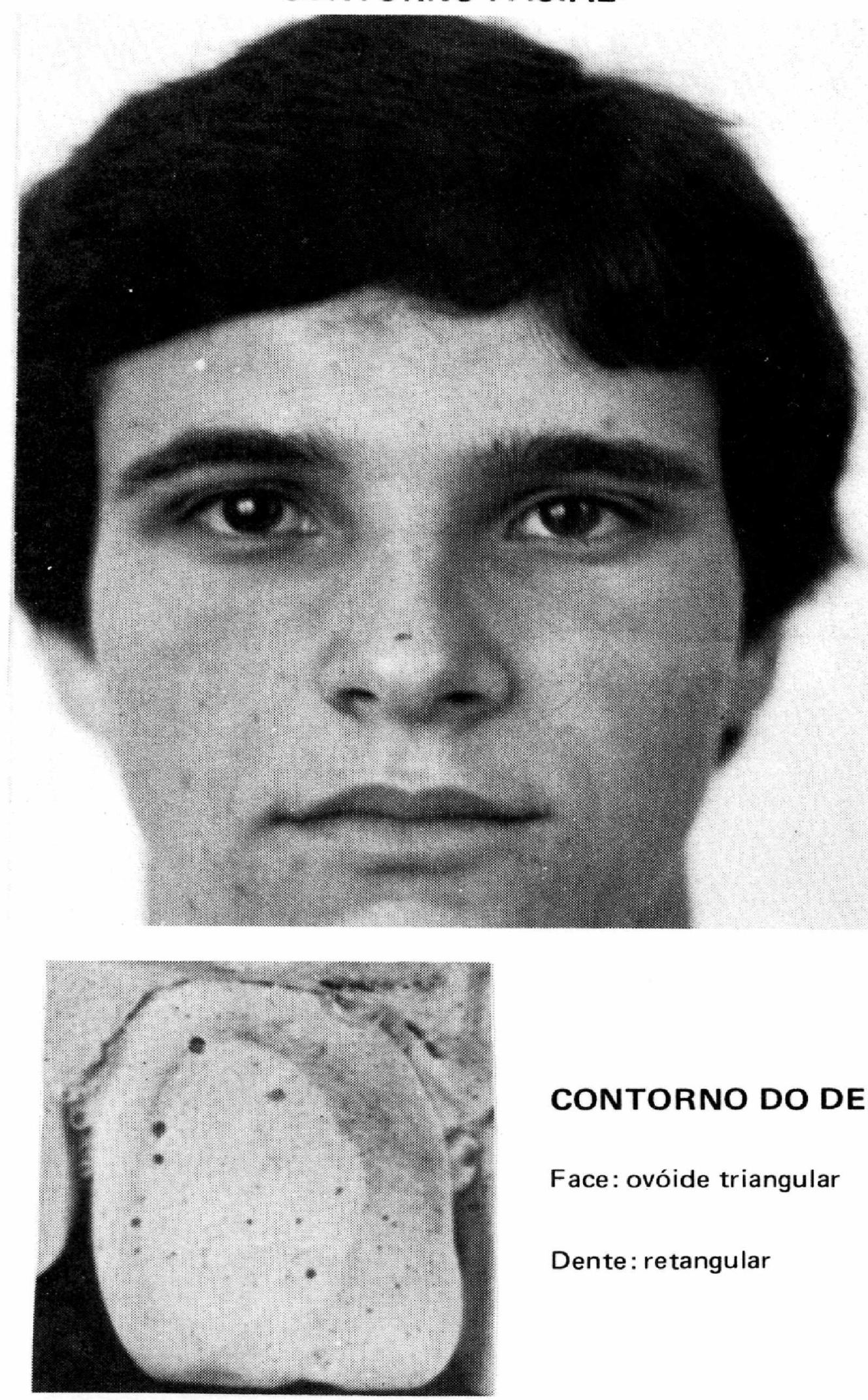

\section{CONTORNO DO DENTE}

Face: ovóide triangular

Dente: retangular

R.Fac.Odont., Porto Alegre, 27:67-89, 1985. 